\title{
Homocysteinstudien i Hordaland
}

\author{
Stein Emil Vollset, Helga Refsum, Ottar Nygård, Aage Tverdal, Grethe S. Tell \\ og Per Magne Ueland \\ Locus for homocystein og relaterte vitaminer, Institutt for samfunnsmedisinske fag, Institutt for farmakologi, \\ Institutt for indremedisin, Universitetet i Bergen og Nasjonalt folkehelseinstitutt, Oslo
}

\begin{abstract}
"The most valuable single study of the influence of risk factors on homocysteine levels is the Hordaland study from Norway". Dette skriver Kilmer McCully i sin bok "The Homocysteine Revolution" og refererer til den første publikasjonen fra Homocysteinundersøkelsen i $1995^{1}$. Vi skal i denne artikkelen kort nevne McCullys og andres tidlige bidrag og oppsummere viktige funn som er gjort i Homocysteinundersøkelsen i Hordaland ${ }^{2-17}$.

I 1991 ble det etablert et samarbeid mellom Statens helseundersøkelser (SHUS) i Oslo og en forskergruppe ved Universitetet i Bergen knyttet til Institutt for farmakologi, Interfakultært kompetansesenter for epidemiologi og Seksjon for medisinsk informatikk og statistikk. Samarbeidet resulterte i at førtiåringsundersøkelsen som SHUS gjennomførte i Hordaland i 1992-93 i samarbeid med kommunene og kommunehelsetjensten ble utvidet til også å omfatte et utvalg 65-67 åringer. I alt deltok 18044 kvinner og menn i alderen 40-42 år (12595 personer), 43-64 år (683 personer) og 65-67 år (4766 personer). Det ble gjort måling av homocystein og cystein i plasma på samtlige deltakere.

Samarbeidet med Statens helseundersøkelser har fortsatt, også etter at SHUS er blitt en del av Nasjonalt folkehelseinstitutt. I forbindelse med Helseundersøkelsen in Hordaland (HUSK) i 1997-99 ble omtrent halvparten av deltakerne i Homocysteinundersøkelsen invitert til ny undersøkelse. Den nye undersøkelsen inkluderte ny homocystein- og cysteinmåling, kostholdsspørreskjema (et samarbeid med Institutt for ernæringsforskning ved Universitetet i Oslo), kognitiv funksjon hos de eldste og forbedret kartlegging av vitaminstatus.
\end{abstract}

\section{BEGYNNELSEN}

Tidlig på 1960-tallet ble leger og forskere i Irland og USA oppmerksomme på den medfødte stoffskiftesykdommen homocystinuri ${ }^{18,19}$. Disse pasientene som har fellestrekk med pasienter med Marfan syndrom hadde betydelig overhyppighet av hjertekarsykdom og samtidig svært høye sirkulerende nivåer av homocystein ${ }^{20}$. En tilgrunnliggende enzymdefekt ble også beskrevet ${ }^{21}$. Kilmer McKully, den gang ved Harvard universitetet, grep fatt $i$ disse problemstillingene og beskrev vaskulær patologi hos pasienter med homocystinuri ${ }^{22}$. Han fremsatte så det som kalles "The homocysteine theory of arteriosclerosis", nemlig at homocystein kunne være en viktig årsaksfaktor for hjertekarsykdom - i befolkningen generelt og ikke bare hos pasienter med homocystinuri ${ }^{23}$. Ved Insti- tutt for farmakologi ved Universitetet i Bergen hadde man lenge vært opptatt av disse problemstillingene ${ }^{24,25}$ og utarbeidet metoder for måling av homocystein ${ }^{26}$ som kunne benyttes i befolkningsstudier ${ }^{27}$.

\section{HVA HAR HORDALANDSSTUDIEN BIDRADD MED}

\section{Kaffe, røyking og risikofaktorer for hjertekarsykdom}

En oppsummering av tverrsnittsresultatene fra Homocysteinstudien i Hordaland ble publisert i $1995^{2}$. Undersøkelsen viste at homocystein i plasma var høyere hos menn enn hos kvinner og stiger med alderen. Det ble også påvist positiv korrelasjon til blodtrykk, kolesterol og en invers korrelasjon til grad av fysisk aktivitet. Et viktig funn, som tidligere hadde vært kontroversielt, var at homocystein var høyere hos røykere enn ikke-røykere. Et originalt funn i Hordalandsundersøkelsen var en klar og sterk sammenheng mellom inntak av kaffe (antall kopper daglig) og homocysteinnivå ${ }^{5}$. Dette funnet er senere bekreftet i randomiserte intervensjonsforsøk med kaffe.

\section{Svangerskap og fodsel}

Homocystein er forhøyet ved mangel på B-vitaminer, spesielt folat og vitamin B12. Folatmangel gir økt risiko for enkelte typer medfødte misdannelser (nevralrørsdefekter) og kan være en årsaksfaktor for andre helseproblemer i svangerskapet og ved fødsel ${ }^{28}$. Gjennom en kopling med data i Medisinsk fødselsregister undersøkte vi sammenhenger mellom homocystein og svangerskapsutfall og komplikasjoner ${ }^{9}$. De viktigste funnene var sterke sammenhenger mellom homocysteinnivå og en rekke svangerskapskomplikasjoner og helseproblemer for barnet, slik som preeklampsi (svangerskapsforgiftning), abruptio (morkakeløsning), for tidlig fødsel og lav fødselsvekt. Antallet medfødte misdannelser var relativt lavt (totalt ca. 190), men vi fant en sammenheng mellom homocystein og nevralrørsdefekter og også klumpfot ${ }^{9}$.

\section{Dodelighet}

Med kopling til dødsårsaksregisteret studerte vi sammenhengen mellom homocystein og dødelighet fra 1992-93 til og med februar 1997 blant de 4766 deltakerne som var 65-67 år ved første gangs undersøkelse ${ }^{12}$. Det var en sterk sammenheng mellom homocystein og dødelighet som var likt fordelt mellom kardiovaskulær (121 dødsfall) og ikke-kardiovaskulær dødelighet (136 dødsfall). Med personer med under $9 \square \mathrm{mol} / \mathrm{L}$ i homocysteinkon- 
sentrasjon som referanse var dødeligheten mer enn doblet hos personer med over $12 \square \mathrm{mol} / \mathrm{L}$ og 3,6-doblet hos personer med over $20 \square \mathrm{mol} / \mathrm{L}$. Sammenhengen mellom homocystein og dødelighet var sterkest hos personer med økt kardiovaskulær risiko eller sykdom (angina pectoris, tidligere slag, hjerteinfarkt eller forhøyet blodtrykk) $^{12}$.

\section{Sykehusinnleggelser for hjertekarsykdom}

Ved hjelp av sykehusenes elektroniske pasientadministrative systemer som inneholder diagnoser ved utskriving og som senere er videreutviklet til et historisk register for Helseregion Vest, kunne vi studere sammenhenger mellom homocystein målt i 1992-93 og senere sykehusinnleggelser for hjertekarsykdom i Homocysteinkohorten $^{13}$. Ved oppfølgning til juli 1998, registrerte vi at $3,7 \%$ av deltakerne i aldersgruppen 40-42 år (12595 kvinner og menn) hadde vært innlagt $\mathrm{i}$ sykehus for hjertekarsykdom i oppfølgningsperioden. Blant disse yngste fant vi ingen sammenheng mellom sykehusinnleggelser og homocystein. Blant de eldste deltakerne ble $16,8 \%$ innlagt i sykehus for hjertekarsykdom. I denne gruppen var det en sterk sammenheng mellom homocysteinnivå og risiko for sykehusinnleggelse ${ }^{13}$.

\section{Angst og depresjon}

I andre runde av Homocysteinundersøkelsen som ble gjennomført i 1998-99, og hvor halvparten av de opprinnelige deltakerne ble invitert til ny undersøkelse, besvarte nær 6000 personer spørsmål om angst og depresjon. Instrumentet som ble brukt var Hospital Anxiety and Depression Scale (HADS) ${ }^{14}$. Homocystein, folat og vitamin $B_{12}$ målt i plasma samt $677 \mathrm{C} \square \mathrm{T}$ polymorfismen $\mathrm{i}$ genet som koder for enzymet metylentetrahydrofolatreduktase, ble sammenholdt med angst- og depresjonskomponentene i HADS-skalaen. Når utfallet ble begrenset til depresjon uten samtidig angst, var det en sammenheng mellom depresjon og forhøyet homocystein og en økt risiko forbundet med TT-varianten av MTHFR $677 \mathrm{C} \square \mathrm{T}$ polymorfismen. TT-genotypen var den sjeldneste varianten, og forekom hos $8,4 \%$ av befolkningen, mens 42 og $50 \%$ hadde henholdsvis CT og $\mathrm{CC}$ genotypene. Det ble ikke funnet noen sammenhenger mellom depresjon og nivåer av folat eller vitamin $\mathrm{B}_{12}$, eller noen av vitaminene og målet for angst. Selv om sammenhengene ikke var svært sterke, styrker disse funnene hypotesen om at folat spiller en rolle i depresjon $^{14}$.

\section{Cystein og homocystein}

Cystein er kjemisk nært beslektet med og en metabolitt av homocystein. Cystein ble målt samtidlig med homocystein i plasma hos alle 18044 deltakere i Homocysteinundersøkelsen i 1992-93. Det første arbeidet på cystein studerte determinanter av cystein og viste at disse til dels var sammenfallende med homocysteins, men med flere viktige unntak. ${ }^{8}$ Cystein var høyere blant de eldste deltakerne og høyere hos unge (40-42 år) menn enn hos unge kvinner. Kolesterol og blodtrykk var assosiert med cystein. Kroppsmasseindeks var en sterk prediktor av cystein og viste ingen klar relasjon til homocystein. En rekke determinanter av homocystein som røyking, vitamin og folatinntak var ikke relatert til cystein. Videre har vi sett på sammenhenger mellom cystein og hjertekarsykdom og dødelighet. Vi studerte 610 dødsfall og 1275 sykehusinnleggelser for hjertekarsykdom med oppfølgning i 6-7 år. Til klar forskjell fra homocystein var det ingen sammenhenger mellom cystein og sykehusinnleggelser for hjertekarsykdom eller dødelighet av alle årsaker. Det var heller ingen sammenheng med dødelighet av hjertekarsykdom ${ }^{17}$.

Vi så også på cystein og svangerskapsutfall og komplikasjoner. Funnene var svakere enn for homocystein, men cystein var, etter justering for homocystein, positivt assosiert med preeklampsi, for tidlig fødsel og lav fødselsvekt. Funnene tydet også på en interaksjon mellom homocystein og cystein, slik at homocystein var en risikofaktor kun når cystein var samtidlig forhøyet ${ }^{16}$. En studie av endringer i cystein mellom undersøkelsen i 1992-93 og den andre undersøkelsen in 1998-99 viste at cystein var relativt stabilt over tid med korrelasjoner mellom de to målingene fra 0,55 til 0,59 . Over 6 års perioden steg cystein med 5-9\% i de ulike alders- og kjønnsgruppene. Den sterkeste prediktoren av endring over tid var endring i kroppsmasseindeks ${ }^{15}$.

\section{DETERMINANTER AV HOMOCYSTEIN, BIOLOGISK PLAUSIBILITET OG MULIGE MEKANISMER}

Homocysteinnivået i serum eller plasma er relatert til en lang rekke forskjellige tilstander som medfødte misdannelser, svangerskapskomplikasjoner ${ }^{29}$, hjertekarsyk$\mathrm{dom}^{30-33}$, enkelte kreftformer ${ }^{34}$ og Alzheimers syk$\operatorname{dom}^{35,36}$. Igjen påvirkes homocysteinnivået av inntak av folat, vitamin $\mathrm{B}_{12}$, vitamin $\mathrm{B}_{6}$, riboflavin ${ }^{37}$, nyrefunksjon, kosthold, røyking, alkoholinntak, enkelte medikamenter, genetiske defekter og polymorfismer som MTHFR (metylentetrahydrofolatreduktase) $677 \mathrm{C} \square \mathrm{T}$ polymorfismen $^{33,38,39}$. En rekke forskjellige mekanismer kan forklare disse observasjonene. For hjertekarsykdoms vedkommende er det observert sammenhenger mellom hyperhomocysteinemi, koagulasjon og blodplatefunksjon $^{40}$. Karfunksjon målt ved såkalt "flow-mediert" vasodilatasjon hemmes av fysiologisk forhøyede homocysteinnivå ${ }^{41}$. For andre tilstander kan sammenhengene mellom homocystein og sykdom kanskje heller forklares via folat som er nødvendig for DNA-syntese og metylering ${ }^{42}$. At TT-varianten av 677C $\square \mathrm{T}$ av MTHFR polymorfismen, som forekommer hos $5-10 \%$ av befolkningen, og som er forbundet med $20-40 \%$ økning i homocysteinnivået, er assosiert med tydelig økt risiko for spina bifida (ryggmargsbrokk) ${ }^{43}$, svakt økt risiko for hjertekarsykdom ${ }^{31}$, og redusert risiko for tykktarms$\mathrm{kreft}^{42}$ gir oss ikke muligheter for å skille mellom effekt av homocystein og folat, men bidrar til et komplekst sett av data som impliserer disse faktorene i patogenese, og som må kompletteres med ny kunnskap. Et viktig spørsmål som vil avklares i løpet av de neste 2-4 år, med 
resultater fra pågående randomiserte kliniske forsøk, er om homocysteinsenkende behandling med folat og andre B-vitaminer bedrer prognosen hos pasienter med hjertekarsykdom $^{44}$

\section{VIDERE STUDIER I HOMOCYSTEINKOHORTEN}

De senere årene er det fremkommet data som gjør at folat, og dermed homocystein som en markør for folat- status, har stor interesse i forbindelse med kreftutvikling. Et viktig prosjekt de nærmeste årene er derfor å kople data fra Kreftregisteret til Homocysteinkohorten. Vi har beregnet at det etter 10 år vil være nærmere 1500 krefttilfeller i kohorten og over 100-200 tilfeller av de vanligste kreftformene. Vi vil også følge dødelighet av alle årsaker videre i kohorten, studere kognitiv funksjon, utnytte kostholdsdataene og arbeide for at biobanken for studien vil kunne utnyttes godt $\mathrm{i}$ årene fremover.

\section{REFERANSER}

1. McCully KS. The homocysteine revolution. Los Angeles: Keats, 1997.

\section{Publikasjoner fra Homocysteinundersøkelsen i Hordaland}

2. Nygård O, Vollset SE, Refsum H, Stensvold I, Tverdal A, Nordrehaug JE, Ueland PM, Kvåle G. Total plasma homocysteine and cardiovascular risk profile. The Hordaland Homocysteine Study. JAMA 1995; 274: 1526-33.

3. Guttormsen AB, Ueland PM, Nesthus I, Nygård O, Schneede J, Vollset SE, Refsum H. Determinants and vitamin responsiveness of intermediate hyperhomocysteinemia ( $\geq 40 \mu \mathrm{mol} / \mathrm{liter}$ ). The Hordaland Homocysteine Study. $J$ Clin Invest 1996; 98: 2174-83.

4. Refsum H, Nygård O, Kvåle G, Ueland PM, Vollset SE. The Hordaland homocysteine study: the opposite tails odds ratios reveal differential effects of gender and intake of vitamin supplements at high and low plasma total homocysteine concentrations. J Nutr 1996; 126: 1244S-8S.

5. Nygård O, Refsum H, Ueland PM, Stensvold I, Nordrehaug JE, Kvåle G, Vollset SE. Coffee consumption and plasma total homocysteine: The Hordaland Homocysteine Study. Am J Clin Nutr 1997; 65: 136-43.

6. Vollset SE, Nygård O, Kvåle G, Ueland PM, Refsum H. The Hordaland Homocysteine Study: Lifestyle and total plasma homocysteine in Western Norway. In: Graham I, Refsum H, Rosenberg IH, Ueland PM, eds. Homocysteine metabolism: From basic science to clinical medicine. Boston: Kluwer Academic Publishers, 1997.

7. Nygård O, Refsum H, Ueland PM, Vollset SE. Major lifestyle determinants of plasma total homocysteine distribution: the Hordaland Homocysteine Study. Am J Clin Nutr 1998; 67: 263-70.

8. El-Khairy L, Ueland PM, Nygård O, Refsum H, Vollset SE. Lifestyle and cardiovascular disease risk factors as determinants of total cysteine in plasma: the Hordaland Homocysteine Study. Am J Clin Nutr 1999; 70: 1016-24.

9. Vollset SE, Refsum H, Irgens LM, Emblem BM, Tverdal A, Gjessing HK, Monsen AL, Ueland PM. Plasma total homocysteine, pregnancy complications, and adverse pregnancy outcomes: the Hordaland Homocysteine study. Am J Clin Nutr 2000; 71: 962-8.

10. Nurk E, Tell GS, Nygård O, Refsum H, Ueland PM, Vollset SE. Plasma total homocysteine is influenced by prandial status in humans: the Hordaland Homocysteine Study. J Nutr 2001; 131: 1214-6.

11. Ueland PM, Nygård O, Vollset SE, Refsum H. The Hordaland Homocysteine Studies. Lipids 2001; 36 Suppl: S33-9.

12. Vollset SE, Refsum H, Tverdal A, Nygård O, Nordrehaug JE, Tell GS, Ueland PM. Plasma total homocysteine and cardiovascular and noncardiovascular mortality: the Hordaland Homocysteine Study. Am J Clin Nutr 2001; 74: $130-6$.

13. Nurk E, Tell GS, Vollset SE, Nygård O, Refsum H, Ueland PM. Plasma total homocysteine and hospitalizations for cardiovascular disease: the Hordaland Homocysteine Study. Arch Intern Med 2002; 162: 1374-81.

14. Bjelland I, Tell GS, Vollset SE, Refsum H, Ueland PM. Folate, vitamin B12, homocysteine, and the MTHFR 677 $\mathrm{C} \square \mathrm{T}$ polymorphism in anxiety and depression. The Hordaland Homocysteine Study. Arch Gen Psychiatry 2003; 60: $618-626$.

15. El-Khairy L, Vollset SE, Refsum H, Ueland PM. Predictors of change in plasma total cysteine: longitudinal findings from the Hordaland homocysteine study. Clin Chem 2003; 49: 113-20.

16. El-Khairy L, Vollset SE, Refsum H, Ueland PM. Plasma total cysteine, pregnancy complications, and adverse pregnancy outcomes: the Hordaland Homocysteine Study. Am J Clin Nutr 2003; 77: 467-72.

17. El-Khairy L, Vollset SE, Refsum H, Ueland PM. Plasma total cysteine, mortality and cardiovascular disease hospitalizations: The Hordaland Homocysteine Study. Clin Chem 2003; 49: 895-900.

\section{Annen litteratur}

18. Gerritsen T, Vaughn JG, Weisman HA. The identification of homocysteine in the urine. Biochem Biophys Res Commun 1962; 9: 493. 
19. Carson NAJ, Neill DW. Metabolic abnormalities detected in a survey of mentally backwards individuals in Northern Ireland. Arch Dis Child 1962; 37: 505-13.

20. Mudd SH, Skovby F, Levy HL, Pettigrew KD, Wilcken B, Pyeritz RE, et al. The natural history of homocystinuria due to cystathionine beta-synthase deficiency. Am J Hum Genet 1985; 37: 1-31.

21. Mudd SH, Finkelstein JD, Irreverre F, Laster L. Homocystinuria: an enzymatic defect. Science 1964; 143: 14435.

22. McCully KS. Vascular pathology of homocysteinemia: implications for the pathogenesis of arteriosclerosis. $A m \mathrm{~J}$ Pathol 1969; 56: 111-28.

23. McCully KS, Wilson RB. Homocysteine theory of arteriosclerosis. Atherosclerosis 1975; 22: 215-27.

24. Ueland PM. Pharmacological and biochemical aspects of S-adenosylhomocysteine and S-adenosylhomocysteine hydrolase. Pharmacol Rev 1982; 34: 223-53.

25. Ueland PM, Refsum H. Plasma homocysteine, a risk factor for vascular disease: plasma levels in health, disease, and drug therapy. J Lab Clin Med 1989; 114: 473-501.

26. Refsum H, Ueland PM, Svardal AM. Fully automated fluorescence assay for determining total homocysteine in plasma. Clin Chem 1989; 35: 1921-7.

27. Arnesen E, Refsum H, Bonaa KH, Ueland PM, Førde OH, Nordrehaug JE. Serum total homocysteine and coronary heart disease. Int J Epidemiol 1995; 24: 704-9.

28. Scholl TO, Johnson WG. Folic acid: influence on the outcome of pregnancy. Am J Clin Nutr 2000; 71: 1295s$1303 \mathrm{~s}$.

29. Eskes TKAB. Homocysteine and human reproduction. In: Carmel R, Jacobsen DW, eds. Homocysteine in health and disease. Cambridge: Cambridge University Press, 2001: 451-66.

30. Ueland PM, Refsum H, Beresford SA, Vollset SE. The controversy over homocysteine and cardiovascular risk. Am J Clin Nutr 2000; 72: 324-32.

31. Wald DS, Law M, Morris JK. Homocysteine and cardiovascular disease: evidence on causality from a metaanalysis. $B M J$ 2002; 325: 1202.

32. Nygård O, Vollset SE, Refsum H, Brattstrom L, Ueland PM. Total homocysteine and cardiovascular disease. $J$ Intern Med 1999; 246: 425-54.

33. Refsum H, Ueland PM, Nygård O, Vollset SE. Homocysteine and cardiovascular disease. Annu Rev Med 1998; 49: 31-62.

34. Blom HJ. Diseases and drugs associated with hyperhomocysteinemia. In: Carmel R, Jacobsen DW, eds. Homocysteine in health and disease. Cambridge: Cambridge University Press, 2001: 331-40.

35. Molloy AM, Weir DG. Homocysteine and the nervous system. In: Carmel R, Jacobsen DW, eds. Homocysteine in health and disease. Cambridge: Cambridge University Press, 2001: 183-98.

36. Clarke R, Smith AD, Jobst KA, Refsum H, Sutton L, Ueland PM. Folate, vitamin B12, and serum total homocysteine levels in confirmed Alzheimer disease. Arch Neurol 1998; 55: 1449-55.

37. Hustad S, Ueland PM, Vollset SE, Zhang Y, Bjorke-Monsen AL, Schneede J. Riboflavin as a determinant of plasma total homocysteine: effect modification by the methylenetetrahydrofolate reductase C677T polymorphism. Clin Chem 2000; 46: 1065-71.

38. De Bree A, Verschuren WM, Kromhout D, Kluijtmans LA, Blom HJ. Homocysteine determinants and the evidence to what extent homocysteine determines the risk of coronary heart disease. Pharmacol Rev 2002; 54: 599-618.

39. Vollset SE, Refsum H, Nygård O, Ueland PM. Lifestyle factors associated with hyperhomocysteinemia. In: Carmel R, Jacobsen DW, eds. Homocysteine in health and disease. Cambridge: Cambridge University Press, 2001: 341-55.

40. Hajjar KA. Homocysteine and hemostasis. In: Carmel R, Jacobsen DW, eds. Homocysteine in health and disease. Cambridge: Cambridge University Press, 2001: 415-24.

41. Lentz SR. Homocysteine and cardiovascular physiology. In: Carmel R, Jacobsen DW, eds. Homocysteine in health and disease. Cambridge: Cambridge University Press, 2001: 441-50.

42. Ueland PM, Hustad S, Schneede J, Refsum H, Vollset SE. Biological and clinical implications of the MTHFR C677T polymorphism. Trends Pharmacol Sci 2001; 22: 195-201.

43. Botto LD, Yang Q. 5,10-Methylenetetrahydrofolate reductase gene variants and congenital anomalies: a HuGE review. Am J Epidemiol 2000; 151: 862-77.

44. Clarke R. Design of clinical trials to test the homocysteine hypothesis of vascular disease. In: Carmel R, Jacobsen DW, eds. Homocysteine in health and disease. Cambridge: Cambridge University Press, 2001: 477-84. 